\title{
Existence theory and stability analysis to a coupled nonlinear fractional mixed boundary value problem
}

\author{
Shahid Saifullah ${ }^{1}$, Akbar Zada $^{1}$, and Sumbel Shahid ${ }^{1}$ \\ ${ }^{1}$ University of Peshawar
}

April 2, 2021

\begin{abstract}
In this manuscript, we conclude a comprehensive approach to a class of nonlinear coupled system of fractional differential equations with mixed type boundary value problem. Subsequently, the solution of coupled system exists and unique under mixed type boundary value conditions with the reference of Schaefer and Banach fixed-point theorems. Further, we developed the Hyers- Ulam stability for the considered problem. Finally, we set an example for the support of our results.
\end{abstract}

\section{Hosted file}

My paper.pdf available at https://authorea.com/users/405471/articles/516435-existence-theoryand-stability-analysis-to-a-coupled-nonlinear-fractional-mixed-boundary-value-problem 